\title{
Clinical Significance of Serial Serum Carcinoembryonic Antigen Values for Treating Rectal Cancer with Preoperative Chemoradiotherapy
}

\author{
Young Jae Ryu, Chang Hyun Kim, Hun Jin Kim, Hyo Kang, Sang Woo Lim, Jung Wook Huh, Jae Kyun Ju, \\ Young Jin Kim, Hyeong Rok Kim \\ Division of Colorectal Surgery, Department of Surgery, Chonnam National University Medical School, Gwangju, Korea
}

Purpose: Preoperative chemoradiotherapy is now widely accepted to treat rectal cancer; however, the prognosis for rectal cancer patients during and after chemoradiotherapy must be determined. The aim of this study was to evaluate the serial serum carcinoembryonic antigen (s-CEA) samples in patients with rectal cancer who underwent radical surgery after concurrent chemoradiotherapy (CRT).

Methods: This study evaluated 236 patients with rectal cancer who received preoperative CRT followed by curative surgery between June 2005 and June 2010. We measured the patient's s-CEA levels pre-CRT, post-CRT and post-surgery. Patients were classified into four groups according to their s-CEA concentrations (group 1, high, high, high; group 2, high, high, normal; group 3, high, normal, normal; group 4, normal, normal, normal). We analyzed the clinicopathologic factors and the outcomes among these groups.

Results: Of the 236 patients, 12 were in group 1, 31 were in group 2, 67 were in group 3, and 126 were in group 4. The 3-year disease-free survival rate in group 1 was poorer than those in group $3(P=0.007)$ and group $4(P<0.001)$. In a univariate analysis, type of surgery, clinical $\mathrm{N}$ stage, pathologic $\mathrm{T}$ or $\mathrm{N}$ stage, lymphovascular invasion, perineural invasion, and CEA group were prognostic factors. A multivariate analysis revealed that type of surgery, pathologic T stage, and lymphovascular invasion were independent prognostic factors; however, no statistical significance was associated with the CEA group. Conclusion: High pre-CRT, post-CRT, and post-surgery s-CEA levels in patients with rectal cancer were associated with high rates of systemic recurrence and poor survival. Therefore, patients with sustained high s-CEA levels during CRT require careful monitoring after surgery.

Keywords: Rectal neoplasms; Carcinoembryonic antigen; Chemoradiotherapy

\section{INTRODUCTION}

Preoperative concurrent chemoradiotherapy (CRT) has become widely accepted for the management of rectal cancer. Preopera-

Received: April 11, 2012 • Accepted: July 18, 2012

Correspondence to: Hyeong Rok Kim, M.D.

Division of Colorectal Surgery, Department of Surgery, Chonnam National University Hwasun Hospital, Chonnam National University Medical School, 322 Seoyang-ro, Hwasun 519-763, Korea

Tel: +82-61-379-7646, Fax: +82-61-379-7661

E-mail:drkhr@jnu.ac.kr

(c) 2012 The Korean Society of Coloproctology

This is an open-access article distributed under the terms of the Creative Commons Attribution NonCommercial License (http://creativecommons.org/licenses/by-nc/3.0) which permits unrestricted noncommercial use, distribution, and reproduction in any medium, provided the original work is properly cited. tive CRT for rectal cancer reduces the local recurrence, reduces toxic effect such as diarrhea and bowel stricture, reduces the tumor size, stabilizes the tumor margin to increase resectability, increases the rate of anal sphincter preservation, and reduces tumor metastasis by eliminating local lymph nodes and blocking metastasis routes [1-3].

Several tumor markers are available to predict the response of patients to preoperative CRT and radical surgery. Among these, serum carcinoembryonic antigen (s-CEA) is currently the most widely used tumor marker for managing patients with colorectal cancer [4]. Several studies have shown that measuring s-CEA by tracking the concentration in patients who underwent radical surgery after CRT is helpful in making a diagnosis and in confirming disease recurrence [5-7]. Pre-CRT s-CEA levels may be a useful tool for predicting the response to CRT, and changes in s-CEA 
before and after CRT might function as an independent prognostic factor in patients with locally advanced rectal cancer [8]. We evaluated the s-CEA levels pre-CRT, post-CRT, and post-surgery in rectal cancer patients and analyzed the disease-free survival (DFS) rates and the prognostic factors in six s-CEA groups.

\section{METHODS}

Medical data on 309 patients with rectal cancer who received pre- operative CRT followed by curative surgery between June 2005 and June 2010 at Chonnam National University Hwasun Hospital were analyzed retrospectively. The exclusion criteria were patients who did not finish CRT, failed to undergo radical excision, had a metastasis at diagnosis, had another malignancy during the followup period, or underwent transanal local excision; 73 patients were excluded based on these criteria. The medical data on the remaining 236 patients were analyzed. A normal s-CEA level is $<5 \mathrm{ng} / \mathrm{mL}$. The s-CEA levels, which were measured 1 week before CRT (pre-

Table 1. Clinicopathologic characteristics according to CEA group

\begin{tabular}{|c|c|c|c|c|c|}
\hline Characteristic & Group 1 & Group 2 & Group 3 & Group 4 & P-value \\
\hline No. of patients & 12 & 31 & 67 & 126 & \\
\hline Age (yr) & & & & & 0.795 \\
\hline Mean \pm SD & $61.2 \pm 14.7$ & $64.5 \pm 10.0$ & $63.1 \pm 11.0$ & $64.0 \pm 10.6$ & \\
\hline Median (range) & $62.5(29-78)$ & $68.0(40-77)$ & $64.0(40-84)$ & $67.0(33-88)$ & \\
\hline Sex & & & & & 0.063 \\
\hline Male & $6(50.0)$ & $23(74.2)$ & $47(70.1)$ & $102(81.0)$ & \\
\hline Female & $6(50.0)$ & $8(25.8)$ & $20(29.9)$ & $24(19.0)$ & \\
\hline Body mass index $\left(\mathrm{kg} / \mathrm{m}^{2}\right)$ & 23.2 & 23 & 23 & 23.7 & 0.728 \\
\hline$\geq 25.0$ & $5(41.7)$ & $8(25.8)$ & $18(26.9)$ & $38(30.2)$ & \\
\hline ASA score & & & & & 0.020 \\
\hline 1 & $6(50.0)$ & $10(32.3)$ & $21(31.3)$ & $22(17.5)$ & \\
\hline 2 & $4(33.3)$ & $17(54.8)$ & 42 (62.7) & 96 (76.2) & \\
\hline 3 & $2(16.7)$ & $4(12.9)$ & $4(6.0)$ & $8(6.3)$ & \\
\hline Tumor size $(\mathrm{cm})$ & & & & & 0.071 \\
\hline Mean \pm SD & $3.63 \pm 1.82$ & $3.11 \pm 1.21$ & $2.92 \pm 1.41$ & $2.64 \pm 1.53$ & \\
\hline Median (range) & $3.75(0.8-6.5)$ & $3.50(1.0-6.3)$ & $2.50(0.1-6.0)$ & $2.40(0.5-9.0)$ & \\
\hline Tumor location (cm) & & & & & 0.083 \\
\hline$A V \geq 8$ & $6(50.0)$ & $8(25.8)$ & $11(16.4)$ & $30(23.8)$ & \\
\hline$A V<8$ & $6(50.0)$ & $23(74.2)$ & 56 (83.6) & 96 (76.2) & \\
\hline Clinical T stage & & & & & 0.099 \\
\hline $\mathrm{T} 1$ or $\mathrm{T} 2$ & $2(16.7)$ & $30(97.8)$ & $3(4.5)$ & 17 (13.5) & \\
\hline T3 or T4 & 10 (83.3) & $1(2.2)$ & 64 (95.5) & $109(86.5)$ & \\
\hline Clinical N stage & & & & & 0.722 \\
\hline NO & $1(8.3)$ & $6(19.4)$ & 21 (31.3) & $49(38.9)$ & \\
\hline N1 or N2 & $11(91.7)$ & 25 (80.6) & $46(68.7)$ & 77 (61.1) & \\
\hline Histological grade & & & & & 0.608 \\
\hline WD or MD & $12(100.0)$ & 28 (90.3) & 59 (88.1) & 115 (91.3) & \\
\hline PD or mucinous & $0(0)$ & $3(9.7)$ & $8(11.9)$ & $11(8.7)$ & \\
\hline Pathologic T stage & & & & & 0.048 \\
\hline урТ0 & $0(0)$ & $2(6.5)$ & $9(13.4)$ & 27 (21.4) & \\
\hline ypT1 & $0(0)$ & $0(0)$ & $3(4.5)$ & $11(8.7)$ & \\
\hline урТ2 & $1(8.3)$ & 7 (22.6) & 15 (22.4) & $34(27.0)$ & \\
\hline урТ3 & 10 (83.3) & $21(67.7)$ & $38(56.7)$ & $51(40.5)$ & \\
\hline
\end{tabular}


CRT), 4 weeks after CRT (post-CRT), and 1 week after surgery (post-surgery), were used to assign the patients to one of six groups: group 1, high, high, high; group 2, high, high, normal; group 3, high, normal, normal; group 4, normal, normal, normal; group 5 , normal, high, high; group 6, normal, normal, high.

All eligible patients with middle or lower rectal cancer, more clinical T3 stage, or positive clinical N stage underwent preoperative CRT. Although having less than clinical T3 stage or negative clinical $\mathrm{N}$ stage, young patients underwent preoperative CRT to preserve the anal sphincter patients. Radiation therapy was executed either as 2- or 3-dimensional conformal therapy using high-energy $\mathrm{X}$ rays ( 6 or $10 \mathrm{MV}$ ). The daily radiation dose was $180 \mathrm{cGy}$, five times per week for 5 weeks for a total of 4,500 cGy, with conventional fractionation encompassing the rectum and intrapelvic lymph node. A dose of $540 \mathrm{cGy}$ was added to the primary and the highrisk areas after reducing the boost field, projecting a total of 5,040 cGy. Chemotherapy was executed by continuously injecting 5-fluorouracil $\left(500 \mathrm{mg} / \mathrm{m}^{2} /\right.$ day $)$ and leucovorin $\left(20 \mathrm{mg} / \mathrm{m}^{2}\right)$ during the first and final weeks of radiotherapy. One round of chemotherapy was conducted in 5 days; two rounds were conducted in total [9].
A digital rectal examination, blood chemistry, s-CEA assay, simple chest X-ray, abdominopelvic computed tomography (CT), pelvic magnetic resonance imaging (MRI), positron emission tomography (PET), colonoscopy, and biopsy were executed as baseline tests. Surgery was conducted 6 to 8 weeks after CRT. High ligation and total mesorectal excision were set as the bases in all patients. Histology was categorized based on the results of a colonoscopic biopsy and was recorded as well differentiated, moderately differentiated, poorly differentiated, and mucinous differentiated. Additionally, perineural and lymphovascular invasions were assessed based on the postoperative pathologic findings. Followup examinations after surgery were done every three months during the first two years and every six months after that. The examinations included a digital rectal exam, laboratory tests, s-CEA assay, chest X-ray and abdominopelvic CT. Chest CT, pelvic MRI, and PET scans were executed based on need. Local recurrence was defined as the presence of a histologically-proven or a radiologically-confirmed tumor in the pelvic cavity or anastomosis within the field of surgery. Systemic recurrence was defined as distant solid organic metastasis, systemic positive lymph nodes, or peri-

Table 1. (Continued from the previous page) Clinicopathologic characteristics according to CEA group

\begin{tabular}{|c|c|c|c|c|c|}
\hline Characteristic & Group 1 & Group 2 & Group 3 & Group 4 & P-value \\
\hline Pathologic N stage & & & & & 0.273 \\
\hline ypNO & $7(58.3)$ & $19(61.3)$ & $52(77.6)$ & $100(79.4)$ & \\
\hline ypN1 & $4(33.3)$ & $8(25.8)$ & $12(17.9)$ & $20(15.9)$ & \\
\hline ypN2 & $1(8.3)$ & $4(12.9)$ & $3(4.5)$ & $6(4.8)$ & \\
\hline TNM stage & & & & & 0.056 \\
\hline I & $1(8.3)$ & $9(29.0)$ & $27(40.3)$ & $65(51.6)$ & \\
\hline$\|$ & $6(50.0)$ & $9(29.0)$ & $27(40.3)$ & $35(27.8)$ & \\
\hline III & $5(41.6)$ & $13(42.0)$ & $13(19.4)$ & $26(20.7)$ & \\
\hline Lymphovascular invasion & $0(0)$ & $5(16.1)$ & $6(9.0)$ & $6(4.8)$ & 0.109 \\
\hline Perineural invasion & $5(41.7)$ & $10(32.3)$ & $14(20.9)$ & $21(16.7)$ & 0.077 \\
\hline TRG $(n=137)$ & & & & & 0.055 \\
\hline 1 & $2(28.6)$ & $3(15.0)$ & $3(8.1)$ & $17(23.0)$ & \\
\hline 2 & $1(14.3)$ & $10(50.0)$ & $8(21.6)$ & $13(17.6)$ & \\
\hline 3 & $4(57.1)$ & $7(35.0)$ & $22(59.5)$ & $29(39.2)$ & \\
\hline 4 & $0(0)$ & $0(0)$ & $4(10.8)$ & $15(20.3)$ & \\
\hline CRM involvement $(n=162)$ & & & & & 0.610 \\
\hline CRM & $4(50.0)$ & $14(70.0)$ & $28(63.6)$ & $51(56.7)$ & \\
\hline CRM & $4(50.0)$ & $6(30.0)$ & $16(36.4)$ & $39(43.3)$ & \\
\hline Surgery type & & & & & 0.020 \\
\hline SSR & $7(58.3)$ & $30(96.8)$ & $59(88.1)$ & 115 (91.3) & \\
\hline APR & $5(41.7)$ & $1(3.2)$ & $8(11.9)$ & $11(8.7)$ & \\
\hline
\end{tabular}

Values are presented as number (\%).

CEA, carcinoembryonic antigen; ASA, American Association of Anaesthetists; AV, anal verge; WD, well differentiated; MD, moderately differentiated; PD, poorly differentiated; TNM, tumor-node-metastasis; TRG, tumor regression grade; CRM, circumferential resection margin; SSR, sphincter-sparing resection; APR, abdominoperineal resection. 
toneal seeding.

We measured age, sex, body mass index, American Association of Anaesthetists (ASA) score, tumor size, tumor location, clinical stage, pathological stage, histological grade, lymphovascular invasion, perineural invasion, tumor regression grade (TRG), circumferential resection margin (CRM) involvement, and surgery type among the groups. Residual tumor mass after preoperative treatment was semi-quantitatively evaluated according to Dworak et al. [10] 5-point grading system for tumor regression. A CRM-positive tumor was defined as a tumor at the CRM or a tumor with a minimal distance between the tumor and the CRM of $\leq 1 \mathrm{~mm}$. A CRM-negative tumor was defined as a tumor with a minimum distance between the tumor and the CRM $>1 \mathrm{~mm}$ [11]. Pathological stage was evaluated based on the categories set forth by 2010 American Joint Committee on tumor-node-metastasis classification, 7th edition.

Of the 236 patients, 214 (90.7\%) received adjuvant chemotherapy. FL (5-fluorouracil [5-FU]/leucovorin, six cycles of monthly bolus intravenous 5 -FU 400 to $425 \mathrm{mg} / \mathrm{m}^{2} /$ day, days 1 to 5 and leucovorin $20 \mathrm{mg} / \mathrm{m}^{2} /$ day, days 1 to 5) was administered to 182 (77.1\%), FOLFOX (5-FU/leucovorin/oxaliplatin, twelve cycles of monthly bolus intravenous $5-\mathrm{FU} 400$ to $425 \mathrm{mg} / \mathrm{m}^{2} /$ day, days 1 to 2 and leucovorin $20 \mathrm{mg} / \mathrm{m}^{2} /$ day, days 1 to 2 , and oxaliplatin 85 $\mathrm{mg} / \mathrm{m}^{2}$, day 1 ) to 18 (7.6\%), UFT (tegafur/uracil, six cycles of UFT $300 \mathrm{mg} / \mathrm{m}^{2} /$ day for 28 days) to 7 , and capecitabine (8 cycles of oral 5 -FU $2,500 \mathrm{mg} / \mathrm{m}^{2}$ for 2 weeks) to 7 patients. The remaining 22 (9.3\%) did not receive chemotherapy because of refusal or poor general condition.

The statistical analysis was done using IBM SPSS ver. 18.0 (IBM Co., Armonk, NY, USA). Frequency differences in each group were checked using the t-test and the chi-squared test. Survival rates were compared with the Kaplan-Meier method and the logrank test. The Cox proportional hazards model was used for the multivariate analysis. A P-value $<0.05$ was considered statistically significant.

\section{RESULTS}

Of the 236 patients, 12 were in group 1, 31 were in group 2, 67 were in group 3 , and 126 were in group 4 . No patients were categorized into group 5 or 6 . Male patients dominated (75.4\%), with a median age of 64 years. The median follow-up interval was 22 months (range, 1 to 75 months). The ASA score was different be- tween groups. When we compared the clinicopathological characteristics among the four groups, the patients in group 1 were more likely to have an advanced pathologic $\mathrm{T}$ stage $(\mathrm{P}=0.048)$ because CRT had little effect on downstaging; they underwent an abdominoperineal resection (APR, $\mathrm{P}=0.020$ ). Nevertheless, tumor size, tumor location, clinical $\mathrm{T}$ or $\mathrm{N}$ stage, histological differentiation, pathologic $\mathrm{N}$ stage, lymphovascular invasion, perineural invasion, TRG, and CRM involvement did not differ among the s-CEA groups (Table 1).

Systemic recurrence occurred frequently in group 1 and was higher than it was in the other groups. The most distant metastatic organ was the lung, followed by the liver. No significant difference in local recurrence was observed among the four groups (Table 2). The 3-year DFS rates of the groups were as follows: group 1,21.9\%; group 2, 59.4\%; group 3, 69\%; group 4, 62.2\%. No significant differences were found between groups 1 and $2(\mathrm{P}=0.093)$, but a significant difference was observed between groups 1 and $3(P=0.007)$ and between groups 1 and $4(\mathrm{P}<0.001)$. No significant differences were observed between groups 2 and $3(\mathrm{P}=0.638)$, between groups 2 and $4(\mathrm{P}=0.587)$, or between groups 3 and $4(\mathrm{P}=0.872)$ (Fig. 1$)$. The 3-year overall survival (OS) rates of the groups were as follows: group 1, 43.7\%; group 2, 81.1\%; group 3, 77.6\%; group 4 ,

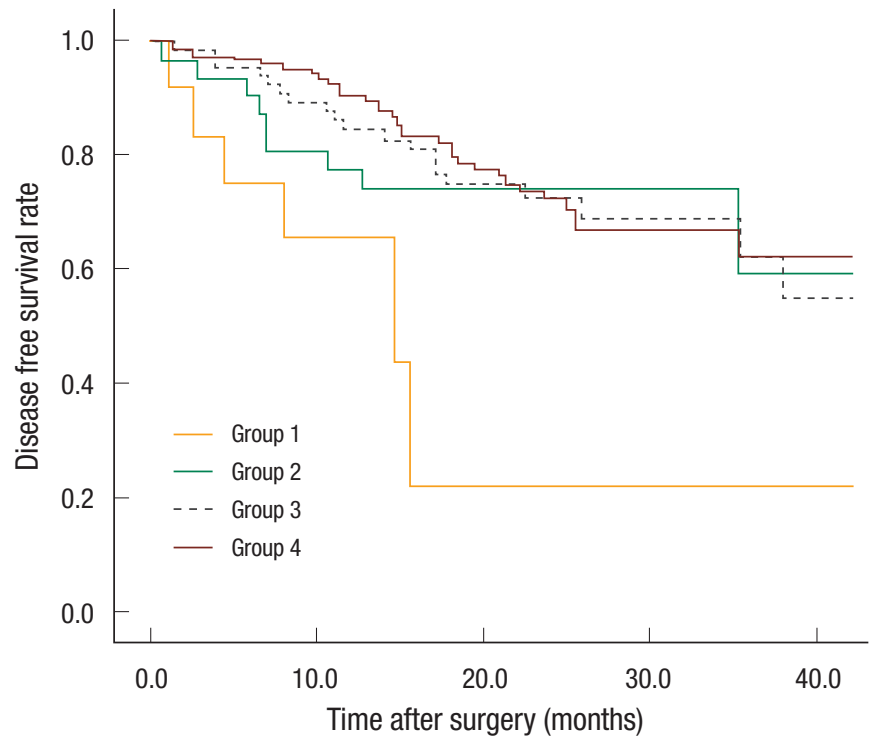

Fig. 1. Disease free survival rate among groups.

Table 2. Recurrence rate according to carcinoembryonic antigen group

\begin{tabular}{llcccc}
\hline & Group 1 & Group 2 & Group 3 & Group 4 & P-value \\
\hline Systemic & $5(41.7)$ & $9(29.0)$ & $11(16.4)$ & $28(22.2)$ & 0.022 \\
Local & $0(0)$ & $0(0)$ & $7(10.4)$ & $4(3.2)$ & 0.137 \\
Systemic + local & $1(8.3)$ & $1(3.3)$ & $1(1.5)$ & $2(1.6)$ & 0.775 \\
Total & $6(50.0)$ & $10(32.3)$ & $19(28.3)$ & $34(27.0)$ & 0.396 \\
\hline
\end{tabular}

Values are presented as number (\%). 
Table 3. Univariate analysis of prognostic factors for disease-free survival

\begin{tabular}{|c|c|c|c|}
\hline & No. of patients (\%) & 3-Year DFS rate & P-value \\
\hline Age (yr) & & & 0.938 \\
\hline$\leq 65$ & $115(48.7)$ & 60.6 & \\
\hline$>65$ & $121(51.2)$ & 61.2 & \\
\hline Sex & & & 0.245 \\
\hline Male & $178(75.4)$ & 60.7 & \\
\hline Female & $58(24.6)$ & 43.1 & \\
\hline Tumor location (cm) & & & 0.194 \\
\hline $\mathrm{AV} \geq 8$ & 55 (23.3) & 72.2 & \\
\hline $\mathrm{AV}<8$ & $181(76.7)$ & 57.5 & \\
\hline Surgery type & & & 0.006 \\
\hline SSR & $211(89.4)$ & 63.5 & \\
\hline APR & 25 (10.6) & 39.1 & \\
\hline Clinical T stage & & & 0.735 \\
\hline $\mathrm{T} 1$ or T2 & $23(9.7)$ & 64.5 & \\
\hline T3 or T4 & $213(90.3)$ & 60.7 & \\
\hline Clinical N stage & & & $<0.001$ \\
\hline NO & $178(75.3)$ & 65.1 & \\
\hline N1 or N2 & $58(24.7)$ & 47.7 & \\
\hline Pathologic T stage & & & $<0.001$ \\
\hline урт0, 1, 2 & $109(46.2)$ & 71.4 & \\
\hline урТ3, 4 & $127(53.8)$ & 49.2 & \\
\hline Pathologic N stage & & & $<0.001$ \\
\hline ypNO & $178(75.4)$ & 65.1 & \\
\hline ypN1, 2 & $58(24.6)$ & 47.7 & \\
\hline Lymphovascular invasion & & & $<0.001$ \\
\hline Positive & $16(6.8)$ & 35.7 & \\
\hline Negative & $220(93.2)$ & 67.9 & \\
\hline Perineural invasion & & & $<0.001$ \\
\hline Positive & 50 (21.2) & 38.1 & \\
\hline Negative & $186(78.8)$ & 67.6 & \\
\hline TRG & & & 0.078 \\
\hline 1 or 2 & $56(23.7)$ & 64.8 & \\
\hline 3 or 4 & $81(34.3)$ & 72.8 & \\
\hline CEA group & & & 0.021 \\
\hline 1 & $12(5.1)$ & 21.9 & \\
\hline 2 & $31(13.1)$ & 59.4 & \\
\hline 3 & 67 (28.4) & 63.1 & \\
\hline 4 & $126(53.4)$ & 62.2 & \\
\hline
\end{tabular}

DFS, disease-free survival; AV, anal verge; SSR, sphincter-sparing resection; APR, abdominoperineal resection; TRG, tumor regression grade; CEA, carcinoembryonic antigen; Group 1, high, high, high; Group 2, high, high, normal; Group 3, high, normal, normal; Group 4, normal, normal, normal.

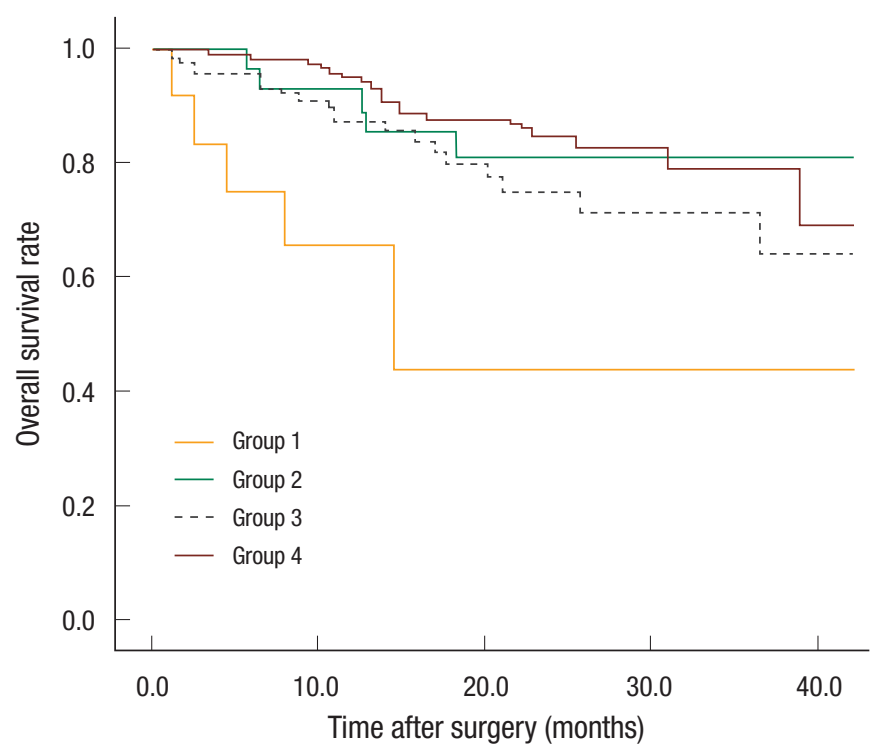

Fig. 2. Overall survival rate among groups.

Table 4. Multivariate analysis of prognostic factors for disease-free survival

\begin{tabular}{lccc}
\hline & Hazard ratio & $95 \% \mathrm{Cl}$ & P-value \\
\hline $\begin{array}{l}\text { Surgery type } \\
\text { SSR }\end{array}$ & 1 & & \\
APR & 2.691 & $1.064-6.805$ & 0.036 \\
Pathologic T stage & & & \\
ypT0, 1, 2 & 1 & & \\
ypT3, 4 & 2.371 & $1.185-4.744$ & 0.015 \\
Pathologic N stage & & & \\
ypN0 & 1 & & 0.056 \\
$\quad$ ypN1, 2 & 1.727 & $0.987-3.021$ & \\
Lymphovascular invasion & & & \\
$\quad$ Negative & 1 & & 0.009 \\
Positive & 5.184 & $1.505-17.853$ & \\
\end{tabular}

Perineural invasion

$\begin{array}{lccc}\text { Negative } & 1 & & \\ \text { Positive } & 1.781 & 0.822-3.859 & 0.143\end{array}$

\section{CEA group}

\begin{tabular}{cccc}
4 & 1 & & \\
3 & 0.910 & $0.513-1.613$ & 0.746 \\
2 & 0.817 & $0.390-1.709$ & 0.591 \\
1 & 1.994 & $0.723-5.497$ & 0.182 \\
\hline
\end{tabular}

$\mathrm{Cl}$, confidence interval; SSR, sphincter-sparing resection; APR, abdominoperineal resection; CEA, carcinoembryonic antigen. 

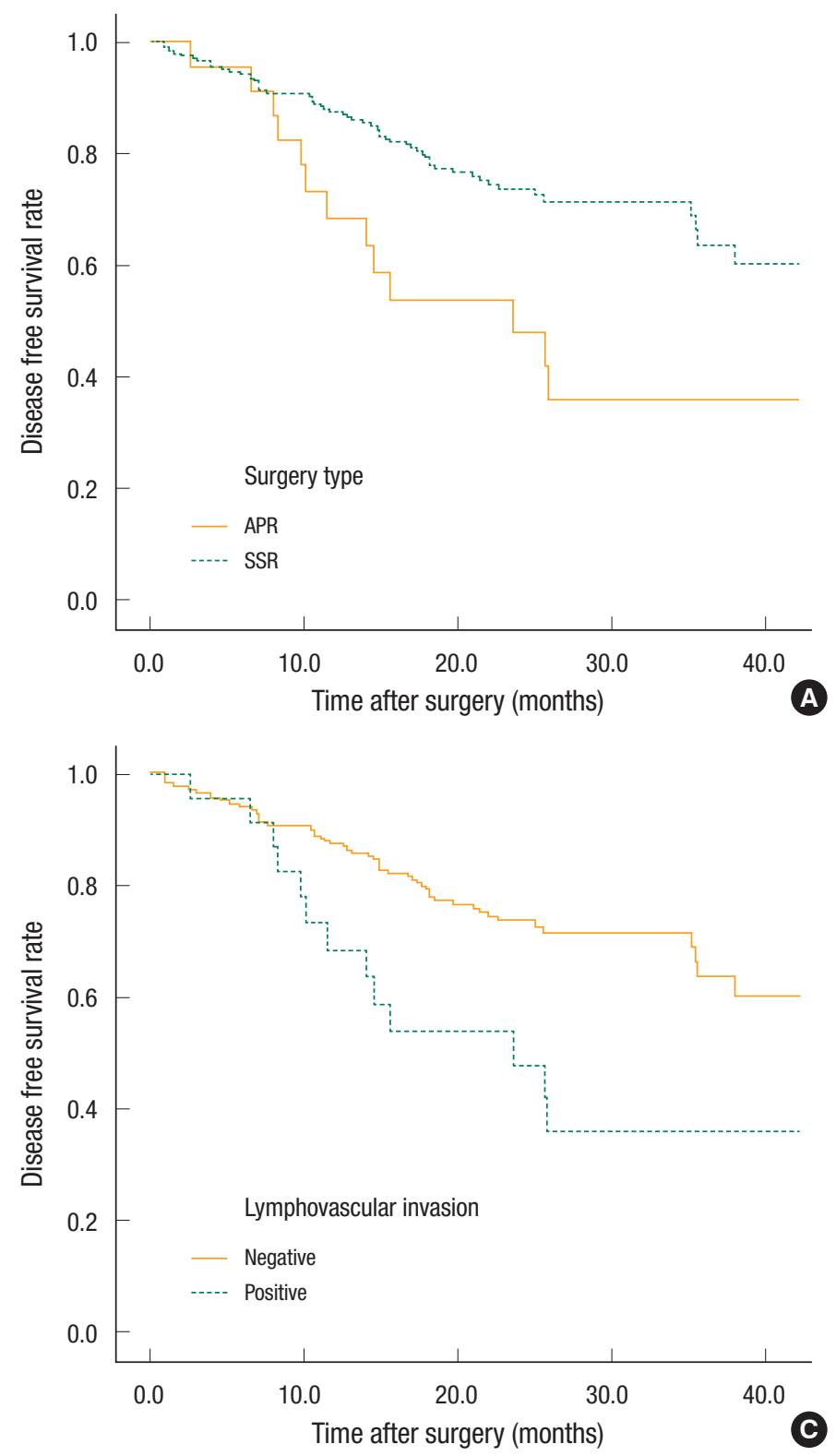

79.1\% (Fig. 2). In the univariate analysis for the prognosis, surgery type (Sphincter-sparing resection vs. APR, $\mathrm{P}=0.006)$, clinical $\mathrm{N}$ stage $(\mathrm{P}<0.001)$, ypT-stage $(\mathrm{P}<0.001)$, ypN-stage $(\mathrm{P}<0.001)$, lymphovascular invasion $(\mathrm{P}<0.001)$, perineural invasion $(\mathrm{P}<$ $0.001)$, and CEA group $(\mathrm{P}=0.021)$ were prognostic factors for DFS (Table 3). However, a multivariate analysis revealed that type of surgery (odds ratio [OR], 2.691; $\mathrm{P}=0.036)$, ypT stage $(\mathrm{OR}, 2.371$; $\mathrm{P}=0.015)$, and lymphovascular invasion $(\mathrm{OR}, 5.184 ; \mathrm{P}=0.009)$ were statistically significant prognostic factors (Table 4, Fig. 3 ).

\section{DISCUSSION}

Since the first description of s-CEA, this marker has been the most

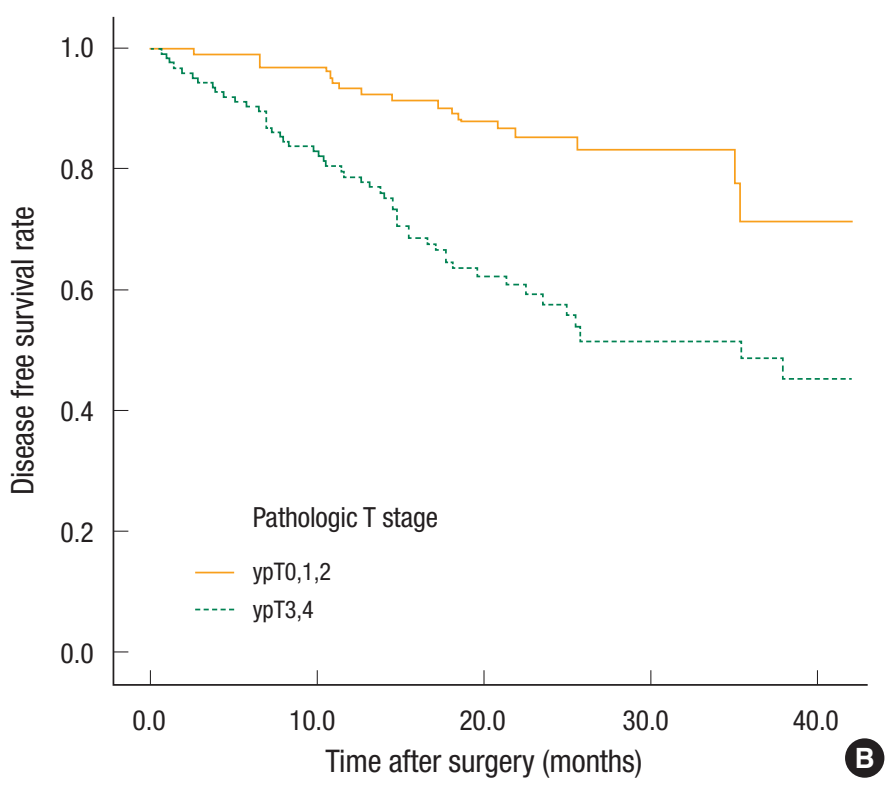

Fig. 3. (A) Disease free survival rate according to surgery type. (B) Disease free survival rate according to pathologic T stage (ypT0,1,2 vs. ypT3,4). (C) Disease free survival rate according to lymphovascular invasion

widely used and readily available tumor marker for managing patients with colorectal cancer. The measurement of s-CEA has been standardized, is easily performed, and is inexpensive compared to other molecular and biochemical tumor marker. Most studies regarding s-CEA in patients with colorectal cancer have focused on the prognostic effect of the preoperative s-CEA concentration, and elevated preoperative s-CEA levels have been related to high recurrence rate $[5,12-15]$.

Known prognostic factors of rectal cancer include tumor size, histological grade, node metastasis, and lymphatic or venous invasion $[6,16]$. A lack of association between pathological stage and tumor recurrence in patients with rectal cancer treated with preoperative radiation or chemoradiation has been reported [17, 
18]. The patients in group 1 in the present study had an advanced T stage because CRT had little effect on downstaging; they also had a tendency to undergo an APR. Chen et al. [19] reported a higher local recurrence rate in patients after an APR compared to those who underwent a sphincter-sparing resection, but surgery type was not identified as an independent risk factor for survival [19].

The CRM status is a major factor in assessing the quality of the surgery and is a powerful prognostic factor; however, a high frequency of CRM-positive patients was shown in present study, which is associated with the distribution of lower rectal cancer or high stage. Of the CRM-positive patients, 68 patients had a CRM status of $1 \mathrm{~mm}$ on the pathologic results.

Pre- and post-CRT s-CEA levels as predictors of response or as prognostic factors in patients with rectal cancer who receive preoperative CRT, as well as a reduction in preoperative s-CEA level after radical surgery, have been associated with improved diseasefree and OS in patients with rectal cancer [20-23]. Wang et al. [24] revealed that preoperative and postoperative s-CEA levels were independent predictors of survival and recurrence. Lin et al. [25] reported that early postoperative s-CEA levels compared to preoperative s-CEA levels were a better prognostic indicator in patients with curable colorectal cancer. Park et al. [6] recognized three s-CEA groups based on their preoperative and early postoperative s-CEA levels. They revealed that patients with rectal cancer who had increased preoperative and early postoperative s-CEA levels showed more frequent systemic failure recurrences and a worse survival rate. In our study, the systemic recurrence rate in group 1 was significantly higher than that in the other groups. Although no correlation with CEA group was identified in the multivariate analysis, the differences in DFS and OS between group 1 and groups 2 to 4 had statistically significance $(P=0.003$, $\mathrm{P}=0.001)$.

The limitations of this study include a relatively-short follow-up period and a small number of specific groups. Additional studies are needed to evaluate the possibility of using serial s-CEA levels as a tool for monitoring the response in patients with rectal cancer who underwent preoperative CRT and radical surgery.

In conclusion, the continuous monitoring of s-CEA levels during CRT and surgery reflected the prognosis for and the frequency of systemic recurrence in patients with rectal cancer. Sustained high s-CEA levels, which means group 1 in this study, during CRT and surgery resulted in high systemic recurrence, as well as poor DFS and OS rates. High s-CEA levels during CRT and surgery were prognostic factors poor outcomes; thus, patients with such levels require careful monitoring after surgery.

\section{CONFLICT OF INTEREST}

No potential conflict of interest relevant to this article was reported.

\section{REFERENCES}

1. Sauer R, Becker H, Hohenberger W, Rodel C, Wittekind C, Fietkau $\mathrm{R}$, et al. Preoperative versus postoperative chemoradiotherapy for rectal cancer. N Engl J Med 2004;351:1731-40.

2. Rodel C, Martus P, Papadoupolos T, Fuzesi L, Klimpfinger M, Fietkau R, et al. Prognostic significance of tumor regression after preoperative chemoradiotherapy for rectal cancer. J Clin Oncol 2005;23:8688-96.

3. Gérard JP, Conroy T, Bonnetain F, Bouche O, Chapet O, ClosonDejardin MT, et al. Preoperative radiotherapy with or without concurrent fluorouracil and leucovorin in T3-4 rectal cancers: results of FFCD 9203. J Clin Oncol 2006;24:4620-5.

4. Berman JM, Cheung RJ, Weinberg DS. Surveillance after colorectal cancer resection. Lancet 2000;355:395-9.

5. Locker GY, Hamilton S, Harris J, Jessup JM, Kemeny N, Macdonald JS, et al. ASCO 2006 update of recommendations for the use of tumor markers in gastrointestinal cancer. J Clin Oncol 2006; 24:5313-27.

6. Park YA, Lee KY, Kim NK, Baik SH, Sohn SK, Cho CW. Prognostic effect of perioperative change of serum carcinoembryonic antigen level: a useful tool for detection of systemic recurrence in rectal cancer. Ann Surg Oncol 2006;13:645-50.

7. Slentz K, Senagore A, Hibbert J, Mazier WP, Talbott TM. Can preoperative and postoperative CEA predict survival after colon cancer resection? Am Surg 1994;60:528-31.

8. Park JW, Lim SB, Kim DY, Jung KH, Hong YS, Chang HJ, et al. Carcinoembryonic antigen as a predictor of pathologic response and a prognostic factor in locally advanced rectal cancer patients treated with preoperative chemoradiotherapy and surgery. Int J Radiat Oncol Biol Phys 2009;74:810-7.

9. Huh JW, Kim HR. Postoperative chemotherapy after neoadjuvant chemoradiation and surgery for rectal cancer: is it essential for patients with ypT0-2N0? J Surg Oncol 2009;100:387-91.

10. Dworak O, Keilholz L, Hoffmann A. Pathological features of rectal cancer after preoperative radiochemotherapy. Int J Colorectal Dis 1997;12:19-23.

11. Hermanek $P$, Junginger $T$. The circumferential resection margin in rectal carcinoma surgery. Tech Coloproctol 2005;9:193-9.

12. Chapman MA, Buckley D, Henson DB, Armitage NC. Preoperative carcinoembryonic antigen is related to tumour stage and long-term survival in colorectal cancer. Br J Cancer 1998;78: 1346-9.

13. Park IJ, Kim HC, Yu CS, Yoo JH, Kim JC. Cutoff values of preoperative s-CEA levels for predicting survivals after curative resection of colorectal cancer. J Korean Med Sci 2005;20:624-7.

14. Park YJ, Park KJ, Park JG, Lee KU, Choe KJ, Kim JP. Prognostic factors in 2230 Korean colorectal cancer patients: analysis of consecutively operated cases. World J Surg 1999;23:721-6.

15. Wolmark N, Fisher B, Wieand HS, Henry RS, Lerner H, LegaultPoisson S, et al. The prognostic significance of preoperative carcinoembryonic antigen levels in colorectal cancer. Results from 


\section{Coloproctology Young Jae Ryu, et al.}

NSABP (National Surgical Adjuvant Breast and Bowel Project) clinical trials. Ann Surg 1984;199:375-82.

16. Nakamura T, Tabuchi Y, Nakae S, Ohno M, Saitoh Y. Serum carcinoembryonic antigen levels and proliferating cell nuclear antigen labeling index for patients with colorectal carcinoma. Correlation with tumor progression and survival. Cancer 1996;77(8 Suppl):1741-6.

17. Kodner IJ, Shemesh EI, Fry RD, Walz BJ, Myerson R, Fleshman JW, et al. Preoperative irradiation for rectal cancer. Improved local control and long-term survival. Ann Surg 1989;209:194-9.

18. Janjan NA, Abbruzzese J, Pazdur R, Khoo VS, Cleary K, Dubrow $R$, et al. Prognostic implications of response to preoperative infusional chemoradiation in locally advanced rectal cancer. Radiother Oncol 1999;51:153-60.

19. Chen ZH, Song XM, Chen SC, Li MZ, Li XX, Zhan WH, et al. Risk factors for adverse outcome in low rectal cancer. World J Gastroenterol 2012;18:64-9.

20. Das P, Skibber JM, Rodriguez-Bigas MA, Feig BW, Chang GJ, Wolff RA, et al. Predictors of tumor response and downstaging in patients who receive preoperative chemoradiation for rectal cancer. Cancer 2007;109:1750-5.

21. Park YA, Sohn SK, Seong J, Baik SH, Lee KY, Kim NK, et al. Serum CEA as a predictor for the response to preoperative chemoradiation in rectal cancer. J Surg Oncol 2006;93:145-50.

22. Yoon SM, Kim DY, Kim TH, Jung KH, Chang HJ, Koom WS, et al. Clinical parameters predicting pathologic tumor response after preoperative chemoradiotherapy for rectal cancer. Int $J$ Radiat Oncol Biol Phys 2007;69:1167-72.

23. Perez RO, Sao Juliao GP, Habr-Gama A, Kiss D, Proscurshim I, Campos FG, et al. The role of carcinoembriogenic antigen in predicting response and survival to neoadjuvant chemoradiotherapy for distal rectal cancer. Dis Colon Rectum 2009;52:1137-43.

24. Wang JY, Lu CY, Chu KS, Ma CJ, Wu DC, Tsai HL, et al. Prognostic significance of pre- and postoperative serum carcinoembryonic antigen levels in patients with colorectal cancer. Eur Surg Res 2007;39:245-50.

25. Lin JK, Lin CC, Yang SH, Wang HS, Jiang JK, Lan YT, et al. Early postoperative CEA level is a better prognostic indicator than is preoperative CEA level in predicting prognosis of patients with curable colorectal cancer. Int J Colorectal Dis 2011;26:1135-41. 